\title{
Polysaccharide-mediated synthesis of melanins from serotonin and other 5-hydroxy indoles
}

\author{
Koen Vercruysse ${ }^{*, 1}$, Astiney Clark ${ }^{1}$, Noor Alatas ${ }^{1}$, Dylan Brooks ${ }^{1}$, Nafisa Hamza ${ }^{1}$ \& \\ Margaret Whalen ${ }^{1}$ \\ ${ }^{1}$ Department of Chemistry, Tennessee State University, Nashville, TN 37209, USA \\ * Author for correspondence: kvercruysse@tnstate.edu
}

\begin{abstract}
Aim: As a continuation of our research on the melanin formation from catecholamines, we studied the polysaccharide-mediated oxidation of serotonin and other 5-hydroxy indoles into melanin-like materials. As for the catecholamines, we observed that many polysaccharides promote the oxidation of such compounds, particularly in the presence of $\mathrm{Cu}^{2+}$. Methodology: The reactions were monitored using reverse phase-HPLC and size-exclusion chromatography techniques. Melanin-like materials were purified through dialysis and characterized using UV-Vis and Fourier transform IR spectroscopic techniques. Results: One such material, synthesized from chondroitin sulfate type $A$ and serotonin in the presence of $\mathrm{Cu}^{2+}$ was found to affect the release of IL-1 $\beta$ and IL- 6 cytokines from immune cells.
\end{abstract}

Lay abstract: The manuscript details our study of the formation of melanin-like pigments from serotonin in the presence of select polysaccharides. Melanin-like pigments have been observed in the brain and their presence is related to pathologies like Parkinson's disease. The melanin-like pigments observed in brain cells are derived from catecholamines like dopamine or norepinephrine. Our research suggests that another important brain compound, serotonin, may make contributions to the appearance of melaninlike pigments in brain tissues.

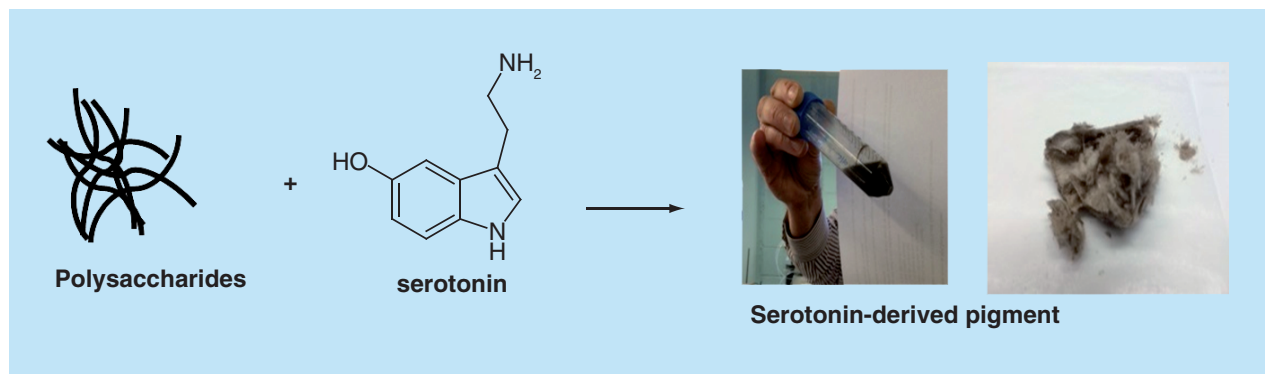

First draft submitted: 10 October 2017; Accepted for publication: 14 December 2017; Published online: 19 January 2018

Keywords: interleukin • melanin • polysaccharide • serotonin • size-exclusion chromatography

In previous report, we described our observations regarding the stimulating effect many, mostly anionic, polysaccharides (PS) had on the auto- or $\mathrm{Cu}^{2+}$-mediated oxidation of catecholamines (CAs) [1]. These reactions resulted in the formation of PS-associated, melanin (MN)-like pigments. We had hypothesized that the $\mathrm{Cu}^{2+}$-mediated oxidation of cationic substances like CAs was enhanced through the complexation of the cation and the substrates to the anionic PS; bringing the cationic substrates and $\mathrm{Cu}^{2+}$ in close proximity to each other. We have expanded these first observations by including a different cationic substrate, serotonin (5-hydroxytryptamine; 5-HT; (1) in Figure 1). We evaluated the $\mathrm{Cu}^{2+}$-mediated oxidation of (1) in the presence of select PS in a similar fashion as was 


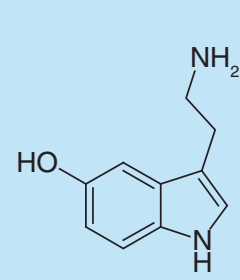

(1)

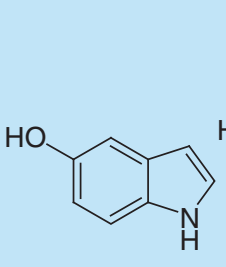

(2)

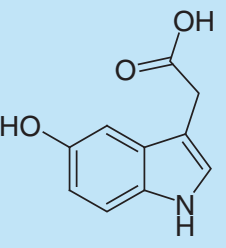

(3)
Figure 1. Chemical structures of the compounds used in this study. (1) serotonin, (2) 5-hydroxyindole and (3) 5-hydroxyindole-3-acetic acid.

done for the CA substrates. In addition, we included 5-hydroxy-indole, (2) in Figure 1, as a neutral substrate and 5-hydroxy-indole-3-acetic acid, (3) in Figure 1, as an anionic substrate in our experiments.

(1) is a powerful biochemical with a multitude of physiological functions as testified by the broad diversity of receptors for which this compound is a ligand [2]. Of relevance for this report is the possible involvement of (1) in the formation of the neuromelanins (NMs). NMs are pigmented substances found in select portions of the brain and are thought to be related to the peripheral MNs found in skin, hair, inner ear or iris [3,4]. The largest or densest accumulation of NMs has been found in the substantia nigra and locus coeruleus portions of the brainstem [5], although neurons in other areas of the brain contain melanized neurons as well [6]. The NM pigments are often found covalently bound to aliphatic chains, lipids or peptides [6-8]. NM-containing neurons are associated with neurodegenerative diseases like Parkinson's or Alzheimer's disease [5,9]. Parkinson's disease is characterized by the demise of melanized, dopamine-secreting neurons in select parts of the brain, for example, the substantia nigra. The NM pigment found in these select parts of the brain is derived from CAs like dopamine or norepinephrine, and its functions appear to be ambiguous. On the one hand, the synthesis of NM removes excess cytosolic catecholic compounds that are often the source of dangerous quinone or semiquinone derivatives [10]. In addition, NM can accumulate potentially damaging Fe- or Cu-based redox ions [6,7,11]. On the other hand, NM released from dying neurons can affect the activity of microglia, promoting the degeneration of neighboring neurons [12]. In general, melanized neurons appear to be more vulnerable to demise than lesser melanized neurons [13].

In addition to the CAs mentioned above, (1) has been investigated as a potential precursor for the formation of NMs [14-16]. Bertazzo et al. studied melanogenesis using (1) and related molecules as substrates for tyrosinase and peroxidase enzymes [14]. In these experiments, oligomerization of (1) by peroxidase was observed. Miller $e$ a al. explored the potential neurotoxicity of MNs derived from (1) [17]. In their studies MNs derived from (1) interacted with unilamellar vesicles made from the phospholipid 1,2-dioleoyl-sn-glycerol-3-phosphocholine, suggesting that such MNs could disrupt cellular membranes.

The reaction between $\mathrm{Cu}^{2+}$ and indole compounds has been studied as far back as 1960; including the observations that darkly pigmented materials can be generated $[18,19]$. Using ${ }^{1} \mathrm{H}$ NMR and mass spectroscopy, Jones et al. studied the reaction between $\mathrm{Cu}^{2+}$ and (1) [20]. They reported on the formation of a dimeric species, but no other oligomeric or polymeric species, and reported on the formation of an insoluble, dark brown material. They also observed that incubating rat pheochromocytoma cells with (1) and $\mathrm{Cu}^{2+}$ resulted in a reduced viability of such cells.

With this report on (1) and related compounds, we would like to expand our hypothesis that many PS can promote the formation of MN-like pigments as was observed for CAs and suggest the possibility that the formation and disposition of such pigments in a tissue may depend on the PS present in the environment.

\section{Materials \& methods \\ Materials}

Chondroitin sulfate type A (CS A; sodium salt from bovine trachea; 70\% with counterbalance CS type C [CS C]), CS C (sodium salt from shark cartilage; $90 \%$ with counterbalance CS A), alginic acid, sodium salt (Algin ${ }^{\circledR}$, sodium alginate), l-carrageenan (commercial grade, type II), fucoidan (FUCO; from Fucus vesiculosus), serotonin. $\mathrm{HCl}$, 5-hydroxyindole and 5-hydroxyindole-3-acetic acid were obtained from Sigma-Aldrich (WI, USA). $\mathrm{CuCl}_{2} \cdot 2 \mathrm{H}_{2} \mathrm{O}$ was obtained from Fisher Scientific (GA, USA). All other reagents were of analytical grade. 


\section{Stock solutions \& reaction mixtures}

Stock solutions of $\mathrm{CuCl}_{2} \cdot 2 \mathrm{H}_{2} \mathrm{O}$ were prepared in water in advance. Stock solutions of all PS were prepared in water 1 day prior to the start of the experiment. The $\mathrm{pH}$ of these PS solutions was measured and ranged between 6.4 and 7.5. Stock solutions of serotonin. $\mathrm{HCl}$ were prepared in water just prior to the start of the experiments. Stock solutions of 5-hydroxy indole and 5-hydroxy indole-3-acetic acid were prepared in methanol:water (1:9 v/v) just prior to the start of the experiments.

\section{UV/Vis spectroscopy}

UV/Vis spectroscopy was performed in microwells of a 96-well microplate using the SynergyHT microplate reader from Biotek (VT, USA). Two hundred microliters aliquots were used and $200 \mu \mathrm{l}$ water as the blank. All measurements were performed at room temperature (RT).

\section{Reverse phase-HPLC analyses}

Reverse phase (RP)-HPLC analyses were performed on a ultra-fast liquid chromatography system equipped with dual LC-6AD solvent delivery pumps and SPD-M20A diode array detector from Shimadzu (MD, USA). Analyses were performed on a BDS Hypersil $C_{8}$ column $(125 \times 4.6 \mathrm{~mm})$ obtained from Fisher Scientific. Analyses were performed in isocratic fashion using a mixture of water:methanol:acetic acid (90:10:0.05\% v/v) as solvent. The sample volume was $20 \mu \mathrm{l}$. Samples were diluted to an approximate final concentration of $0.1 \mathrm{mM}$ for (1), (2) or (3) and centrifuged prior to analysis.

\section{Size-exclusion chromatography}

Size-exclusion chromatography (SEC) analyses were performed on a Breeze 2 HPLC system equipped with two 1500 series HPLC pumps and a model 2998 Photodiode array detector from Waters, Co. (MA, USA). Analyses were performed using an Ultrahydrogel 500 column $(300 \times 7.8 \mathrm{~mm})$ obtained from Waters, Co. and in isocratic fashion using a mixture of $25 \mathrm{mM} \mathrm{Na}$ acetate:methanol:acetic acid (90:10:0.05\% v/v) as solvent. Samples were diluted with SEC solvent to an approximate final concentration of $0.1 \mathrm{mM}$ for (1), (2) or (3) and centrifuged prior to analysis, centrifuged. The sample volume was $20 \mu \mathrm{l}$.

\section{Dialysis \& freeze drying}

Select samples were dialyzed using Spectrum Spectra/Por RC dialysis membranes with MW cut-off of $3.5 \mathrm{kDa}$ obtained from Fisher Scientific. Select dialyzed materials were frozen overnight and dried using a Labconco FreeZone Plus 4.5L benchtop freeze-dry system obtained from Fisher Scientific. All dried materials were kept in a freezer till further analysis.

\section{Fourier transform IR spectroscopy}

Fourier transform IR (FT-IR) spectroscopic scans were made using the NicoletiS10 instrument equipped with the SmartiTR Basic accessory from ThermoScientific (MA, USA). Scans were taken with a resolution of $4 \mathrm{~cm}^{-1}$ between 650 and $4000 \mathrm{~cm}^{-1}$ at RT using a $\mathrm{KBr}$ beam splitter and DTGS KBr detector. Each spectrum represents the accumulation of 24 scans.

\section{Atomic absorption spectroscopy}

Atomic absorption spectroscopy measurements were made using the AAnalyst 300 instrument from Perkin Elmer (MA, USA). Standard solutions containing known concentrations of $\mathrm{CuCl}_{2}$ were prepared in water and used to calibrate the instrument for the analyses. Stock solution of pigment material was prepared in water and analyzed as such.

\section{Preparation of monocyte-depleted peripheral blood mononuclear cells}

Peripheral blood mononuclear cells (PBMCs) were isolated from leukocyte filters (PALL-RCPL or RC2D) obtained from the Red Cross Blood Bank Facility (TN, USA) as described elsewhere [21]. Leukocytes were retrieved from the filters by back-flushing them with an elution medium (sterile phosphate-buffered saline [PBS] solution containing $5 \mathrm{mM}$ disodium EDTA and 2.5\% [w/v] sucrose) and collecting the eluent. The eluent was layered onto FicollHypaque $(1.077 \mathrm{~g} / \mathrm{ml})$ and centrifuged at $1200 \times \mathrm{g}$ for $50 \mathrm{~min}$. Granulocytes and red cells pelleted at the bottom of the tube while the PBMCs floated on the Ficoll-Hypaque. Mononuclear cells were collected and washed with 
PBS $(500 \times g, 10 \mathrm{~min})$. Following washing, the cells were layered on bovine calf serum for platelet removal. The cells were then suspended in RPMI-1640 complete medium (Fisher Scientific) which consisted of RPMI-1640 supplemented with $10 \%$ heat-inactivated bovine calf serum, $2 \mathrm{mM} \mathrm{L}$-glutamine and $50 \mathrm{U}$ penicillin $\mathrm{G}$ with $50 \mu \mathrm{g}$ streptomycin $/ \mathrm{ml}$. This preparation constituted PBMCs. Monocyte-depleted PBMCs (10-20\% CD16, $10-20 \%$ $\mathrm{CD} 56^{+}, 70-80 \% \mathrm{CD}^{+}, 3-5 \% \mathrm{CD} 19^{+}, 2-20 \% \mathrm{CD}^{4} 4^{+}$) were prepared by incubating the cells in glass petri dishes $(150 \times 15 \mathrm{~mm})$ at $37^{\circ} \mathrm{C}$ and air $/ \mathrm{CO}_{2}, 19: 1$ for $1 \mathrm{~h}$. This cell preparation is referred to as monocyte-depleted (MD)-PBMCs.

\section{PBMC studies}

Test compounds were dissolved in water 1 day prior to the start of the experiment. For the IL-1 $\beta$ release experiment, $25 \mu \mathrm{l}$ of the test compounds (and the appropriate controls) were added to $500 \mu \mathrm{l}$ of MD-PBMC cell suspension. For the IL- 6 release, $5 \mu$ of the test compounds (and the appropriate controls) were added to $1000 \mu \mathrm{l}$ of MD-PBMC cell suspension. The concentration of the cells was 750,000 in $500 \mu \mathrm{l}$ of cell culture media. After addition of the compounds, the mixtures were incubated at $37^{\circ} \mathrm{C}$ in an atmosphere containing $5 \% \mathrm{CO}_{2}$ for $24 \mathrm{~h}$ after which cell viability was assessed and supernatants were collected and stored at $-80^{\circ} \mathrm{C}$ until assay.

\section{Cell viability}

Cell viability was assessed at the end of each exposure period. Viability was determined using the trypan-blue exclusion method. Briefly, cells were mixed with trypan blue and counted using a hemocytometer. The total number of cells and the total number of live cells were determined for both control and treated cells to determine the percent viable cells.

\section{IL-1 $\beta$ or IL- 6 secretion assay}

IL-1 $\beta$ and IL- 6 levels in isolated samples were assessed using the OptEIA ${ }^{\text {TM }}$ ELISA for human IL- $1 \beta$ kit and human IL-6, respectively (BD Biosciences, CA, USA). In brief, capture antibody diluted in coating buffer was applied to wells of 96-well flat-bottom microplates specifically designed for ELISA (Fisher Scientific). The plates were incubated overnight at $4{ }^{\circ} \mathrm{C}$, and then excess capture antibody was removed by washing the plate three-times with wash buffer (PBS containing 0.05\% [v/v] Tween-20 [PBST]). The wells were then treated with blocking buffer to prevent nonspecific binding and the plate was sealed and incubated at RT for $1 \mathrm{~h}$. Blocking buffer was removed with three washes of PBST, and cell supernatants and IL-1 $\beta$ or IL- 6 standards were added to dedicated wells; the plate was resealed and incubated at RT for $2 \mathrm{~h}$. The plate was then washed five-times with PBST and this was followed by incubation with IL-1 $\beta$ or IL- 6 detection antibody, which was subsequently conjugated with horseradish peroxidase. The plate was then washed seven-times and a substrate solution was added for $30 \mathrm{~min}$ at RT to produce a colored product. The incubation with the substrate was ended by addition of acid and the absorbance was measured at $450 \mathrm{~nm}$ on a Thermo Labsystems Multiskan MCC/340 plate reader (Fisher Scientific).

\section{Results}

Preliminary studies using RP-HPLC

When aqueous solutions of (1), (2) or (3) (concentrations about $1 \mathrm{mM}$ ) are kept at RT or $37^{\circ} \mathrm{C}$, with or without the presence of $\mathrm{Cu}^{2+}$ (concentrations below $0.1 \mathrm{mM}$ ), then little change in color of these solutions was observed. However, when such solutions contained select PS, then slowly, typically after overnight reactions, dark brown to black colors appeared in some of these mixtures. Such observations hinted to the possibility that select PS, for example, CS A or FUCO could promote the $\mathrm{Cu}^{2+}$-mediated oxidation of (1) and related compounds to MN-like pigments, similar to what was observed for reactions between PS and CAs [1]. Aliquots from such reaction mixtures could be analyzed using RP-HPLC or SEC. Typical RP-HPLC profiles are shown in Figure 2. In such analyses (1) had a retention time of about $9.5 \mathrm{~min}$, while (2) and (3) had retention times of about $3.75 \mathrm{~min}$. RP-HPLC profiles of reaction mixtures containing PS would show peaks with retention times of about 1 min that are associated with the PS material. RP-HPLC profiles from reaction mixtures involving (2) or (3) contained peaks of unknown identity with retention times of about 7.5 or $2.5 \mathrm{~min}$, respectively. Mixtures containing $1 \mathrm{mM}(\mathbf{1}), 2.5 \mathrm{mg} / \mathrm{ml}$ $\mathrm{CS} \mathrm{A}$ and between 0 and $1.3 \mathrm{mM} \mathrm{Cu}^{2+}$ were incubated overnight at $37^{\circ} \mathrm{C}$. Aliquots of the reaction mixtures were diluted and analyzed using RP-HPLC and the AUC for the signal at $275 \mathrm{~nm}$ for the peak corresponding to (1) was calculated. In addition, the absorbance at $400 \mathrm{~nm}$ of the undiluted reaction mixtures was measured in a microplate. Figure 3 presents the results thus obtained. In the absence of any CS A, a decline (up to 60\%) in AUC of the 


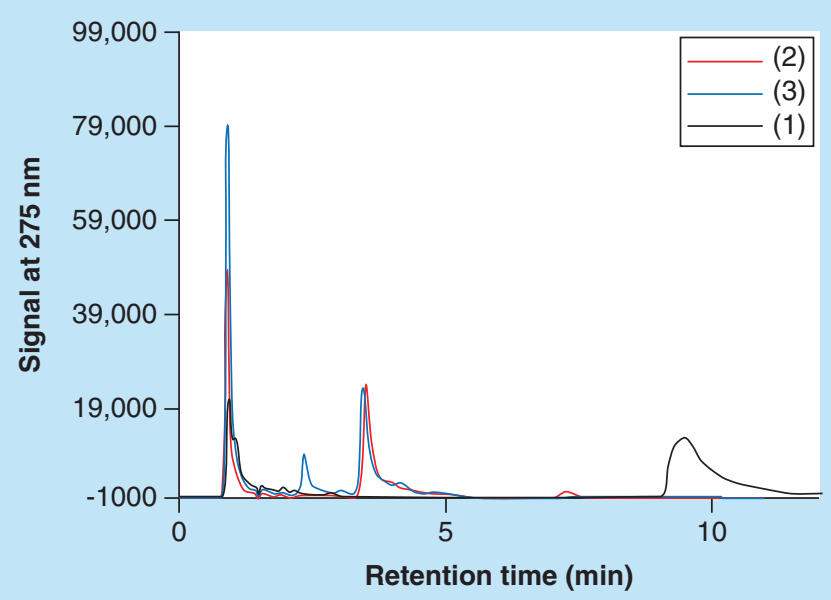

Figure 2. Reverse phase-HPLC profiles of aliquots of reaction mixtures containing chondroitin sulfate type A, $\mathrm{Cu}^{2+}$ and (1) (black line), (2) (red line) or (3) (blue line). The reaction mixtures contained $1 \mathrm{mM}(1),(2)$ or (3), $8 \mathrm{mg} / \mathrm{ml}$ chondroitin sulfate type $\mathrm{A}$ and $0.1 \mathrm{mM} \mathrm{Cu}^{2+}$ and were kept at $37^{\circ} \mathrm{C}$ overnight.

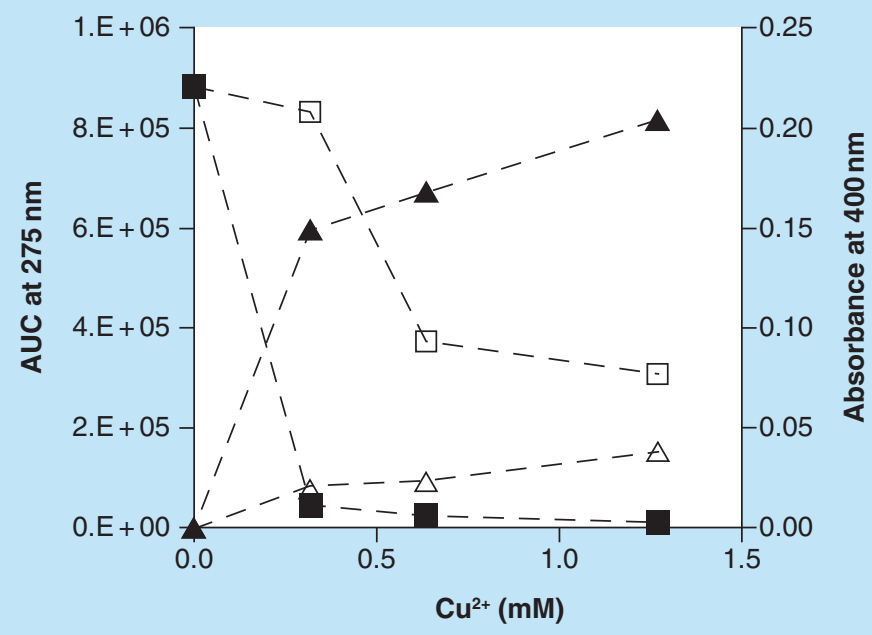

Figure 3. Effect of $\mathrm{Cu}^{2+}$ concentration on reactions containing (1), chondroitin sulfate type $\mathrm{A}$ and $\mathrm{Cu}^{2+}$. AUC corresponding to (1) for reactions with (closed squares) or without (open squares) CS A and absorbance at $400 \mathrm{~nm}$ of the reaction mixtures with (closed triangles) or without (open triangles) CS A. The reaction mixtures contained $1 \mathrm{mM}$ (1), $2.5 \mathrm{mg} / \mathrm{ml} \mathrm{CS} \mathrm{A}$ and between 0 and $1.3 \mathrm{mM} \mathrm{Cu}^{2+}$ and were incubated overnight at $37^{\circ} \mathrm{C}$.

CS A: Chondroitin sulfate type A.

peak corresponding with (1) and an increase in absorbance at $400 \mathrm{~nm}$ could be observed with increasing $\mathrm{Cu}^{2+}$ concentrations. In the presence of CS A a near total disappearance of (1) from the reaction mixtures was observed in the presence of the highest concentration of $\mathrm{Cu}^{2+}$ tested. This was associated with the presence of a much darker color of the reaction mixtures as judged from visual observations and by measuring the absorbance of the mixtures at $400 \mathrm{~nm}$. Clearly, in the presence of CS A, a much stronger reactivity between (1) and $\mathrm{Cu}^{2+}$ had occurred. A similar pattern of results was obtained for reactions in the presence of CS C, carrageenan (CARRA), alginate or FUCO (results not shown). In addition, CARRA and FUCO appeared to promote color formation from (1) in the absence of any added $\mathrm{Cu}^{2+}$ (results not shown).

The effect of $\mathrm{Cu}^{2+}$ concentration on the reaction with (2) or (3) in the presence of CS A was briefly investigated. Higher concentrations of CS A were used in these experiments as visual observations made during preliminary experiments had indicated that (2) and (3) reacted less compared with (1). Mixtures containing $1 \mathrm{mM}$ (2) or (3), 

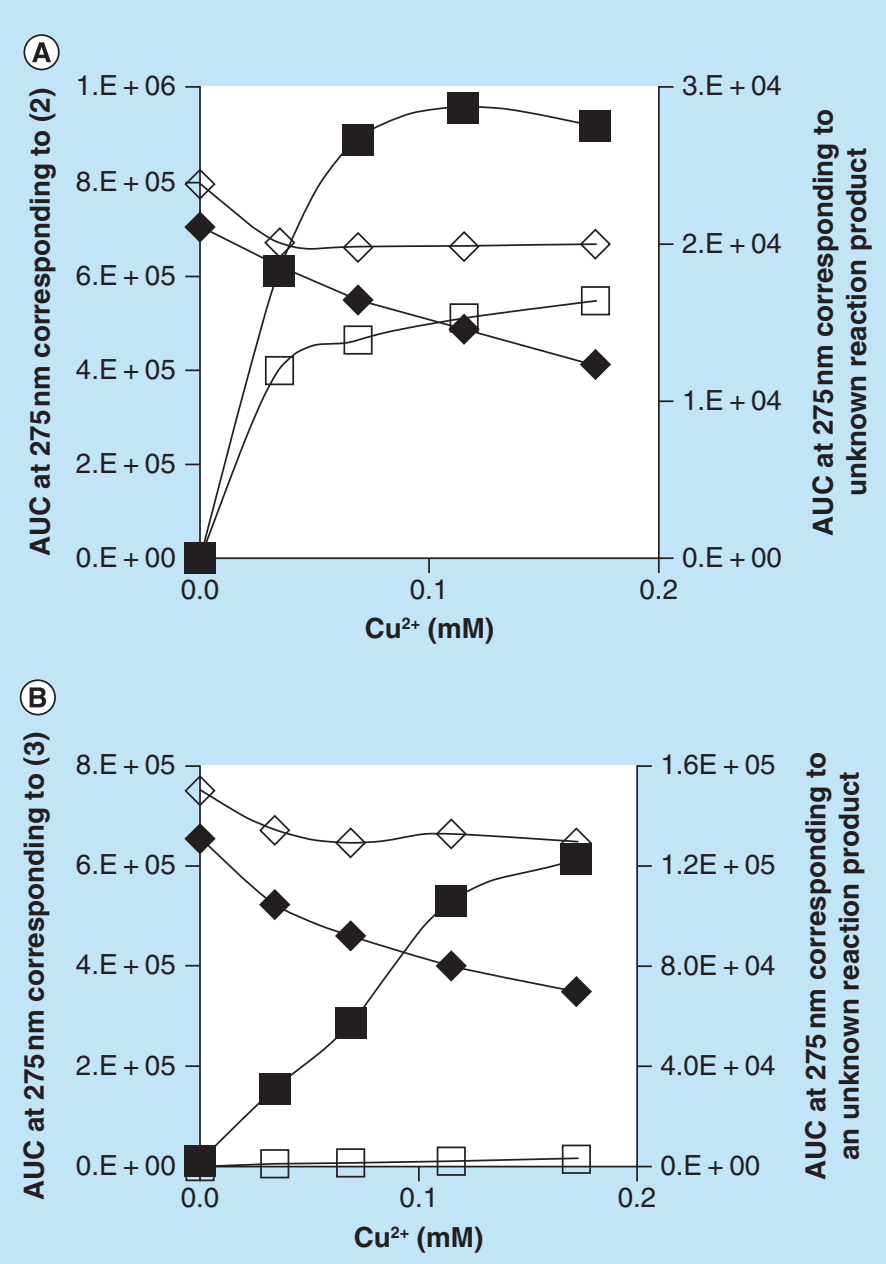

Figure 4. Effect of $\mathrm{Cu}^{2+}$ on reactivity of (2) and (3). Effect of $\mathrm{Cu}^{2+}$ concentration on the reaction between (2) (panel A) or (3) (panel B), CS A and $\mathrm{Cu}^{2+}$. AUC corresponding to (2) or (3) (diamonds) for reactions with (closed symbols) or without (open symbols) CS A and AUC corresponding to an unknown reaction product (squares) as a function of $\mathrm{Cu}^{2+}$ concentration present. The reaction mixtures contained $1 \mathrm{mM}(2)$ or (3), 0 or $8 \mathrm{mg} / \mathrm{ml} \mathrm{CS} \mathrm{A}$ and between 0 and $0.17 \mathrm{mM} \mathrm{Cu}^{2+}$ and were incubated overnight at $37^{\circ} \mathrm{C}$. CS A: Chondroitin sulfate type $A$.

between 0 and $0.17 \mathrm{mM} \mathrm{Cu}^{2+}$ and 0 or $8 \mathrm{mg} / \mathrm{ml} \mathrm{CS} \mathrm{A} \mathrm{were} \mathrm{incubated} \mathrm{overnight} \mathrm{at} 37^{\circ} \mathrm{C}$. Aliquots from the reaction mixtures were diluted and analyzed using RP-HPLC. The AUC (signal at $275 \mathrm{~nm}$ ) for the peaks corresponding to (2) or (3) and the unknown reaction product with retention time of about 7.5 or $2.5 \mathrm{~min}$ (see Figure 2) were determined. Figure 4, panel A, illustrates the decline in AUC of the peak corresponding to (2) and the increase in the AUC of the peak corresponding to the reaction product formed as a function of the $\mathrm{Cu}^{2+}$ concentration present in the mixtures. Figure 4, panel B, illustrates similar results for the reactions involving (3). The results indicate that in the presence of CS A, there was a Cu-dependent decline in the AUC of the peak corresponding to (2) or (3). However, there was no near-total disappearance of the substrate as was observed for the experiments involving (1). In the absence of CS A, a modest decline in the AUC corresponding to (2) or (3) was observed as a function of the $\mathrm{Cu}^{2+}$ concentration. For the experiments involving (2), there was a $\mathrm{Cu}^{2+}$-dependent increase in AUC of the peak corresponding to the reaction product formed, but this increase was much higher in the presence of CS A than in the absence of this PS. For the experiments involving (3), there was a $\mathrm{Cu}^{2+}$-dependent increase in AUC of the peak corresponding to the reaction product formed in the presence of CS A, but hardly any such reaction product was observed in the absence of the PS. 
Figure 5. Size-exclusion chromatography profiles of aliquots of reaction mixtures containing chondroitin sulfate type A, $\mathrm{Cu}^{2+}$ and (1) (solid line) or (3) (dotted line). The reaction mixtures contained $1 \mathrm{mM}$ (1) or (3), $8 \mathrm{mg} / \mathrm{ml}$ chondroitin sulfate type $\mathrm{A}$ and $0.1 \mathrm{mM} \mathrm{Cu}^{2+}$ and were kept at $37^{\circ} \mathrm{C}$ overnight.
Figure 6. Kinetic profile of the AUC (signal at $275 \mathrm{~nm}$ ) corresponding to (1) as determined by size-exclusion chromatography analysis. Reaction mixtures contained $2 \mathrm{mM}$ (1) and 0 (open symbols) or 0.05 (closed symbols) $\mathrm{mM} \mathrm{Cu}^{2+}$ and $0 \mathrm{mg} / \mathrm{ml}$ polysaccharides (triangles), $4 \mathrm{mg} / \mathrm{ml}$ chondroitin sulfate type A (diamonds) or $4 \mathrm{mg} / \mathrm{ml}$ fucoidan (squares).
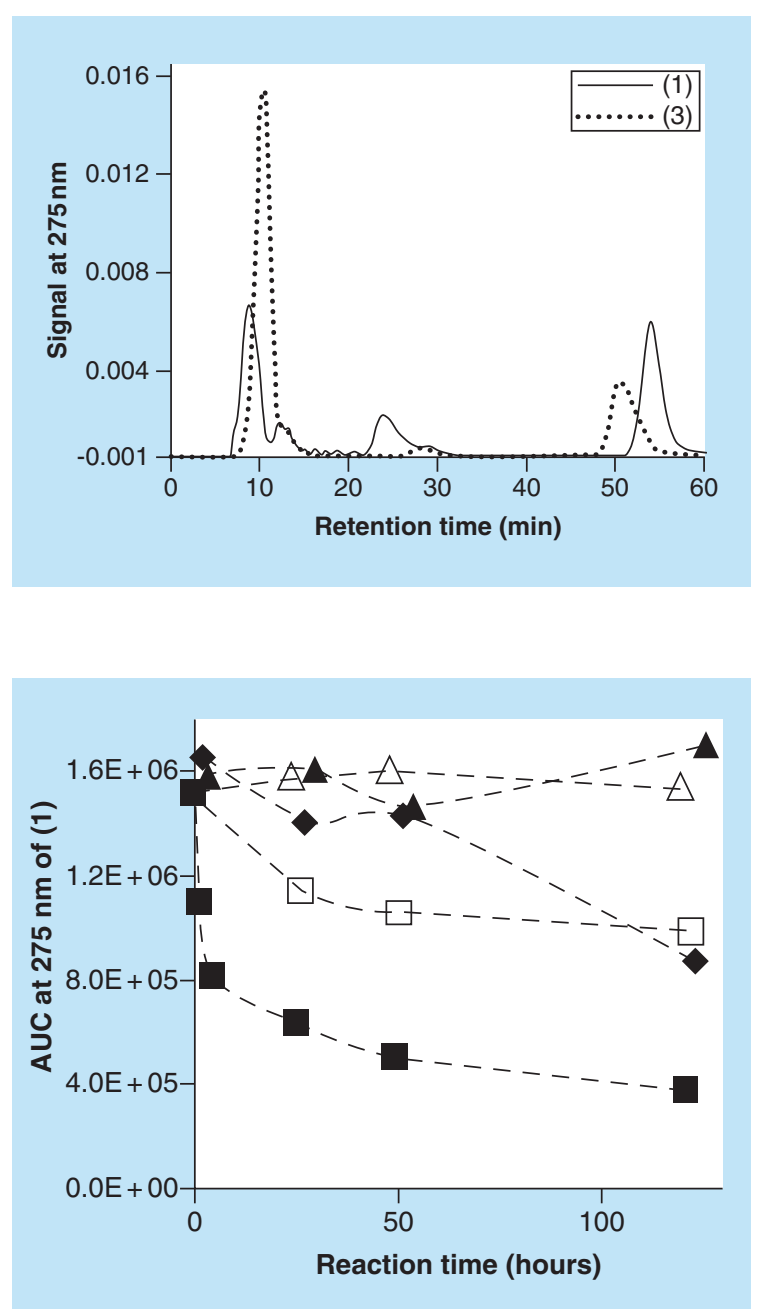

\section{Preliminary studies using SEC}

As discussed for the experiments involving CAs, SEC is a versatile technique to monitor: the presence and disappearance of the substrate of the reaction; the characteristics of the PS-associated materials; the potential presence of nanoparticles; and the presence of other reaction products [1]. SEC analyses for reaction mixtures containing (2) were not routinely performed as this compound appeared to exhibit an extensive retention on the SEC column used and its retention time for these analyses could not be determined. Figure 5 shows typical SEC profiles for reactions involving (1) or (3) in the presence of CS A and $\mathrm{Cu}^{2+}$. The peaks with retention times of $<15$ min correspond to high molecular mass materials, for example, PS or PS/pigment complexes. The peaks with retention times of about 51 or $57 \mathrm{~min}$ correspond to (3) or (1), respectively. The peaks with retention times of about 25 or 28 min correspond to unidentified reaction products that appeared during the reactions involving (1) or (3), respectively. An unknown reaction product was observed in the RP-HPLC profiles for reaction mixtures involving (3) (see Figure 3), but not for the reaction mixtures involving (1).

A kinetic study was set up involving reactions containing $2 \mathrm{mM}(\mathbf{1}), 4 \mathrm{mg} / \mathrm{ml} \mathrm{CS} \mathrm{A} \mathrm{or} \mathrm{FUCO} \mathrm{and} 0$ or $0.05 \mathrm{mM}$ $\mathrm{Cu}^{2+}$ incubated at $37^{\circ} \mathrm{C}$. Over a period of multiple days, aliquots from these reaction mixtures were diluted, centrifuged and analyzed using SEC. Figure 6 illustrates the AUC (signal at $275 \mathrm{~nm}$ ) of the peak corresponding to (1) as a function of the reaction time. In the absence of any PS, with or without $\mathrm{Cu}^{2+}$, no significant decline in AUC related to (1) could be observed. The reaction in the presence of CS A and $\mathrm{Cu}^{2+}$ resulted in a decline of about $40 \%$ in the AUC associated with (1) at the end of the experiment. In the presence of CS A, without any added $\mathrm{Cu}^{2+}$, no significant decline in AUC associated with (1) could be observed (results not included in Figure 6). In the presence of FUCO, the AUC associated with (1) declined much more rapidly and by the end of the experiment had declined to about $65 \%$ of starting value in the absence of any added $\mathrm{Cu}^{2+}$ and about $25 \%$ of starting value 


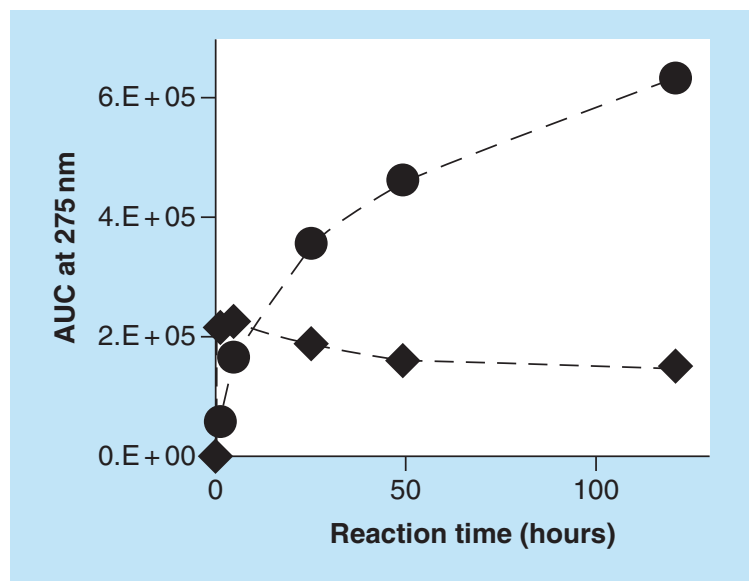

Figure 7. Kinetic profile of the AUC (signal at $275 \mathrm{~nm}$ ), as determined by size-exclusion chromatography analysis, corresponding to fucoidan (circles) and unknown reaction product (diamonds). The reaction mixture contained $2 \mathrm{mM}$ (1), $0.05 \mathrm{mM} \mathrm{Cu}^{2+}$ and $4 \mathrm{mg} / \mathrm{ml}$ fucoidan.

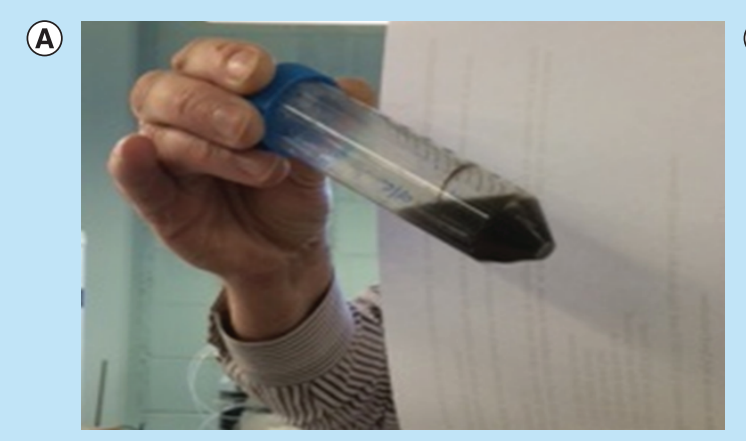

(B)

Figure 8. Photographs of serotonin-based melanin. Photograph of the crude reaction mixture (panel A) containing $14 \mathrm{mM}$ (1), $52 \mathrm{mg} / \mathrm{ml}$ chondroitin sulfate type $A$ and $0.7 \mathrm{mM} \mathrm{Cu}{ }^{2+}$ after 6 days of reaction at $37^{\circ} \mathrm{C}$ and of the dialyzed and dried material (panel B).

in the presence of $\mathrm{Cu}^{2+}$. Associated with these experiments, we also monitored the AUC of the unknown reaction product with retention time of about $25 \mathrm{~min}$ and the AUC of the peak associated with PS materials. Figure 7 illustrates these results for the reaction between (1) and FUCO in the presence of $\mathrm{Cu}^{2+}$. The results show a rapid increase in the AUC of the unknown reaction product, followed by a very slow decline. In addition, the UV-Vis absorbance associated with the PS materials steadily increased as a function of the reaction time. A similar profile for the changes in AUC associated with PS and reaction products had been observed for the reaction between select PS and CAs [1].

\section{Large-scale reactions}

A $10 \mathrm{ml}$ mixture containing $520 \mathrm{mg} \mathrm{CS} \mathrm{A}, 1.3 \mathrm{mg} \mathrm{CuCl} 2.2 \mathrm{H}_{2} \mathrm{O}\left(0.7 \mathrm{mM} \mathrm{Cu}^{2+}\right)$ and $30 \mathrm{mg}$ (1) (14 mM) was kept at $37^{\circ} \mathrm{C}$ for 6 days. Higher concentrations, compared with the small-scale preliminary experiments, of CS A, $\mathrm{Cu}^{2+}$ and (1) were used to maximize the formation of pigment materials. Following this reaction, a photograph of the mixture was taken and is shown in Figure 8, panel A. Figure 8, panel B, shows a photograph of the dialyzed and lyophilized material thus obtained. The photograph in Figure 8, panel A, shows a darkly colored solution and a ring of dark material adhered to the side of the plastic tube used as reaction vessel. Figure 9 shows the SEC profiles (signal at $275 \mathrm{~nm}$ ) of a diluted aliquot of the reaction mixture before and after exhaustive dialysis. At the end of the reaction the SEC profile shows peaks corresponding to: (1) (retention time about $55 \mathrm{~min}$ ); an unknown reaction product typically observed under these reaction conditions (retention time about $25 \mathrm{~min}$ ); CS A (retention time about $10 \mathrm{~min}$ ); and a very high molecular mass material (peak retention time of about $6 \mathrm{~min}$ ). Following dialysis, the mixture contains no (1), but still has peaks corresponding to the three other items mentioned above. When the SEC profile of the dialyzed mixture is viewed at $400 \mathrm{~nm}$, then only the peaks corresponding to CS A and the very high molecular mass material are observed (results not shown). This indicates that the material with absorbance 


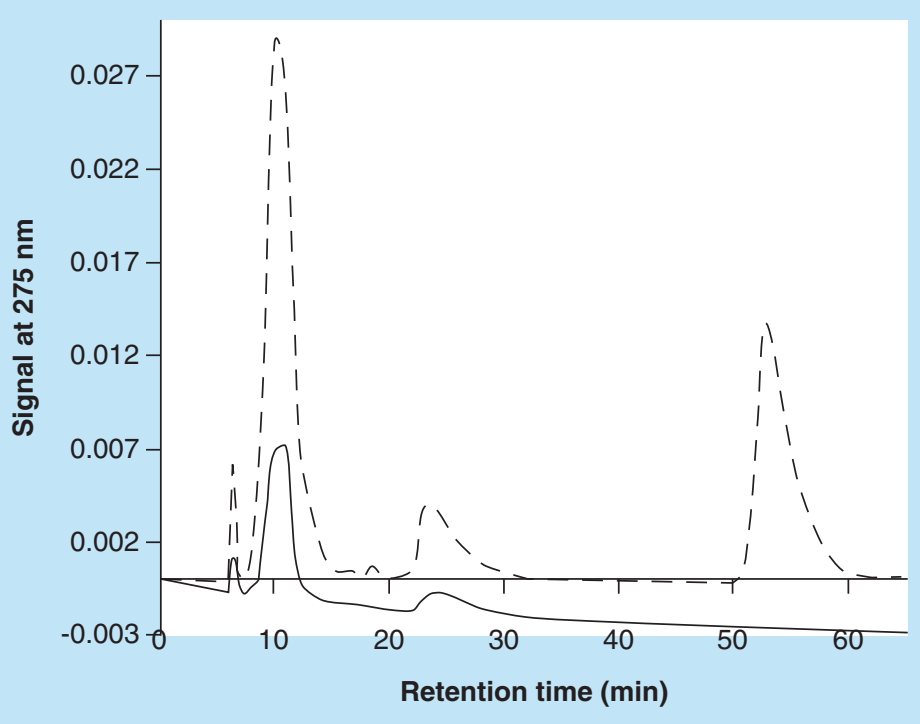

Figure 9. Size-exclusion chromatography profiles of diluted aliquots from the reaction mixture (dotted line) shown in Figure 8, panel $\mathrm{A}$ and the reaction mixture after dialysis against water (solid line).

Figure 10. Photographs of 5-hydroxyindole-based melanin. Photograph of reaction mixtures involving (2) and, top, from left to right, water, chondroitin sulfate type $A$ and chondroitin sulfate type $C$ or, bottom, left to right, fucoidan, carrageenan and NaOAc after 6 days at room temperature.

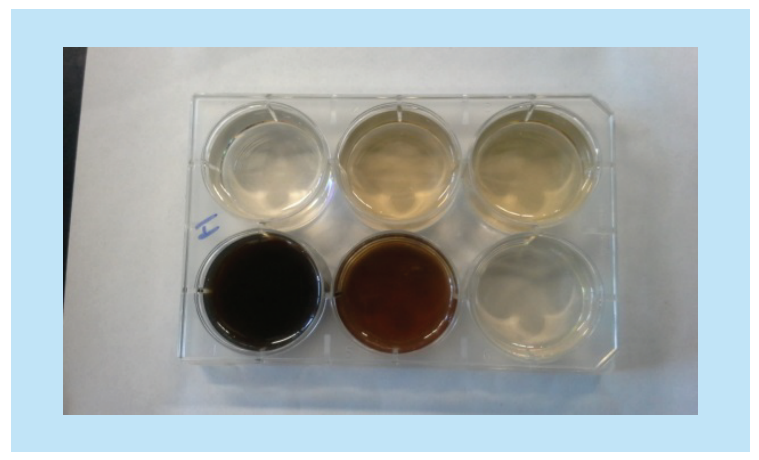

in the visible range is associated with the CS A peak and with the very high molecular mass material with peak retention time of about $6 \mathrm{~min}$.

Large-scale reactions were set up between (2) or (3) and select PS or sodium acetate in the absence of any added cation. Between 30 and $35 \mathrm{mg}$ of (2) or (3) was placed into the well of a cell culture dish and $10 \mathrm{ml}$ water was added. To these, about $100 \mathrm{mg}$ of CS A, CS C, FUCO, CARRA or NaOAc was added. The cell culture dish was covered and kept at RT for up to 30 days. Figure 10 shows a photograph of the experiment involving (2) after 6 days of reaction. Dark colors had developed in the mixtures containing FUCO or CARRA and much lighter colors in all the other mixtures. Figure 11 shows a photograph of the experiment involving (3) after 30 days of reaction. Reaction mixtures containing (3) very slowly developed a distinct reddish color and after 30 days of reaction intense colors were observed in the mixtures containing CS A, CS C, CARRA or FUCO, but not in the mixtures containing $\mathrm{NaOAc}$ or the control experiment. Mold growth had occurred in the mixture containing CS A (indicated with the arrow in Figure 11), but not in any of the other mixtures. UV-Vis spectra of aliquots from select mixtures were recorded and are shown in Figure 12. The spectrum of the reaction mixture involving (2) and FUCO showed enhanced absorbance in the entire visible range of the light spectrum, without any distinct features in the spectrum. Select reaction mixtures involving (3) yielded spectra with a distinct absorbance maximum around $530 \mathrm{~nm}$. Select reaction mixtures involving (2) were dialyzed against water and this purification was monitored using RP-HPLC analyses to ensure that all unreacted (2) had disappeared. The reaction mixture containing CS C and (3) was dialyzed against water, but all colored substances diffused out of the dialysis bag and after a couple of changes of water, the interior of the dialysis bag appeared to be colorless (results not shown). It was presumed that 

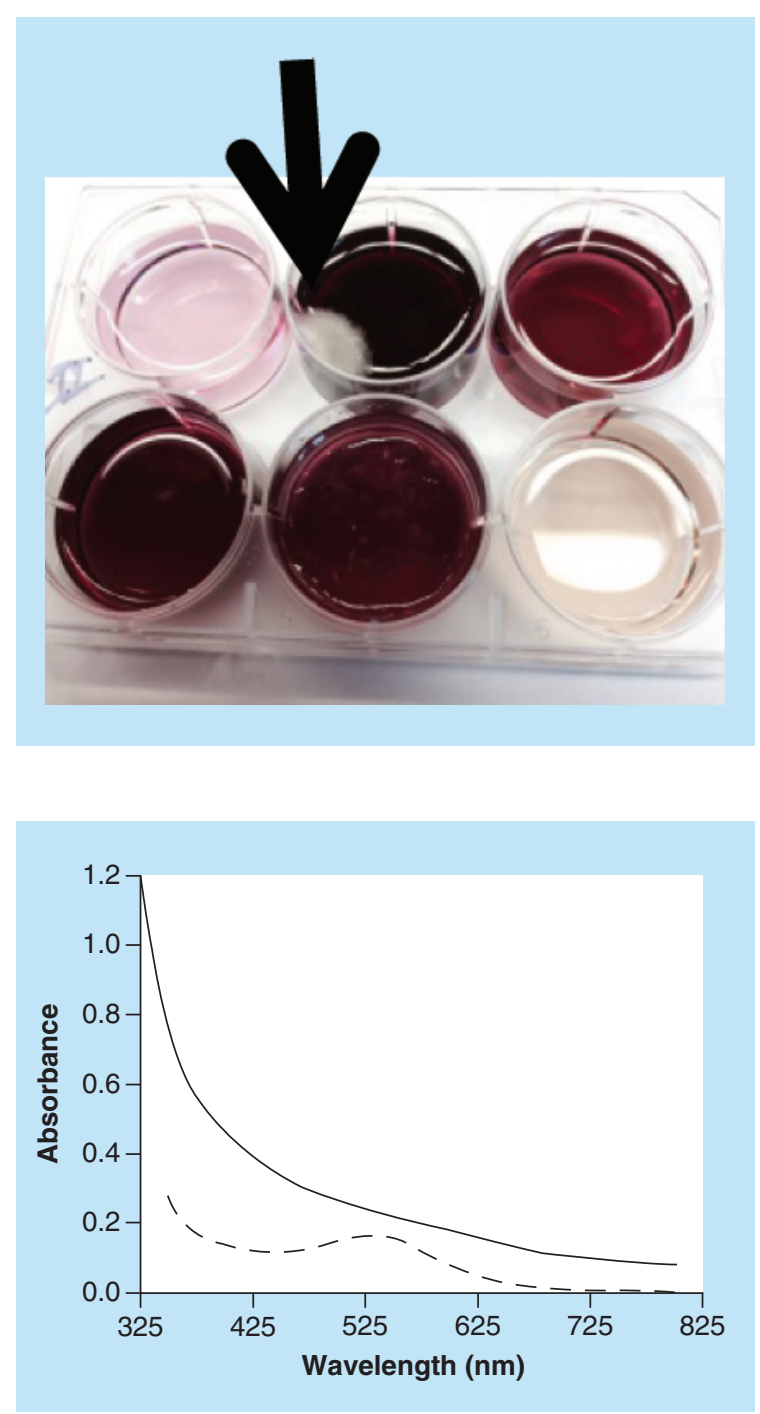

Figure 11. Photographs of 5-hydroxyindole-3-acetic acid-based melanins. Photograph of reaction mixtures involving (3) and, top, from left to right, water, chondroitin sulfate type $A$ and chondroitin sulfate type $C$ or, bottom, left to right, fucoidan, carrageenan and $\mathrm{NaOAC}$ after 30 days at room temperature. The arrow points to mold growth that had occurred in the mixture containing chondroitin sulfate type A.

Figure 12. UV-Vis spectra of reaction mixtures involving (2) and fucoidan (solid line) and (3) and chondroitin sulfate type $C$ (dashed line) from the reaction mixtures shown in Figures 10 \& 11, respectively.

the reaction between (3) and PS yielded a low molecular mass chromophore, but that no PS-pigment complex was generated.

\section{Characterization of pigments}

The dialyzed and dried material shown in Figure 8, panel B, was redissolved in water to a concentration of $5 \mathrm{mg} / \mathrm{ml}$. Atomic absorption spectroscopy analysis was performed on this pigment solution and on $\mathrm{Cu}^{2+}$ standards with concentrations between 0 and $0.4 \mathrm{mM}$. The results indicated that following exhaustive dialysis the dried pigment material contained $1.4 \mu \mathrm{g} \mathrm{Cu}{ }^{2+} / \mathrm{mg}$ material.

An FT-IR spectrum of the dried pigment material was recorded and is presented in Figure 10, panels A \& B. Figure 10, panel A, compares the FT-IR spectra of (1) and the pigment material described above. Figure 10, panel $\mathrm{B}$, compares the FT-IR spectra of CS A and this same pigment material. FT-IR spectra of select dialyzed and dried pigment materials made from (2) were recorded and typical results are presented in Figure 14, panels A and B. Figure 14, panel A, compares the FT-IR spectra of (2) and the pigment material made from FUCO and (2) in the absence of $\mathrm{Cu}^{2+}$. Figure 14, panel B, compares the FT-IR spectra of FUCO and the same pigment material as in Figure 14, panel A.

Interleukin release from immune cells

The IL-1 $\beta$ and -6 release from immune cells in the presence of CS A or the pigment material discussed earlier (see Figure 8) is shown in Figure 15, panels A and B, respectively. CS A and the dried pigment were dissolved in water 
(A)

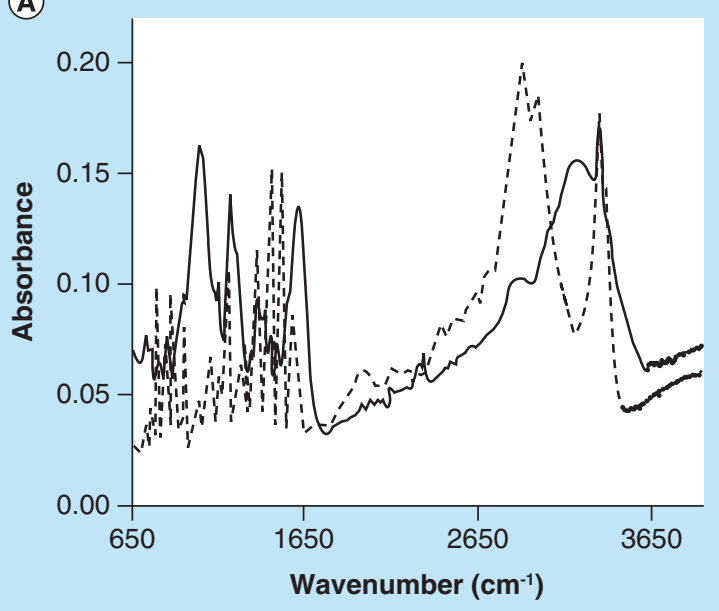

(B)

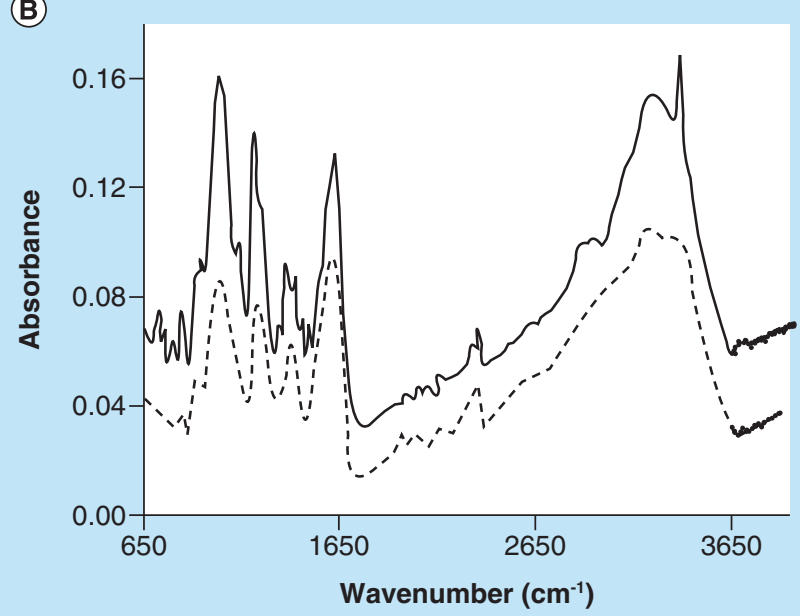

Figure 13. Fourier transform IR scans of the pigment (solid line in both panels) made from (1) as shown in Figure 8, panel B and (1) (dashed line in panel A) or chondroitin sulfate type A (dashed line in panel B).

(A)

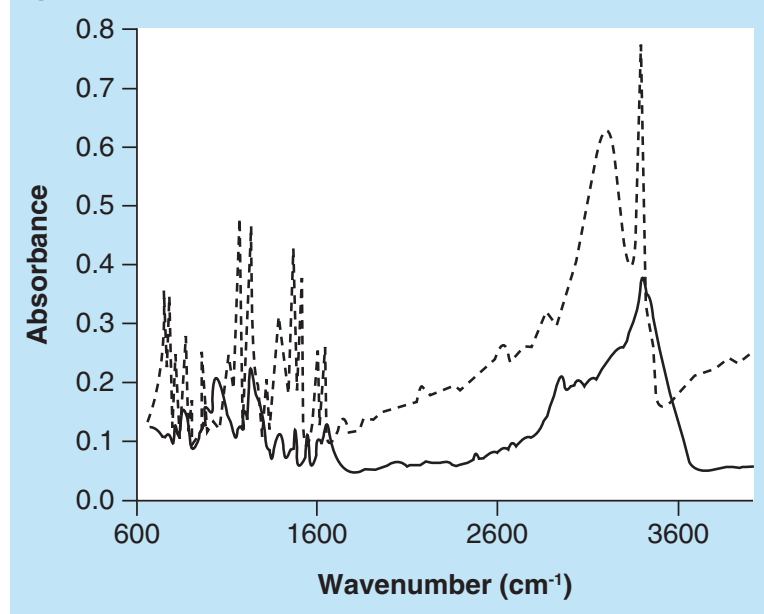

(B)

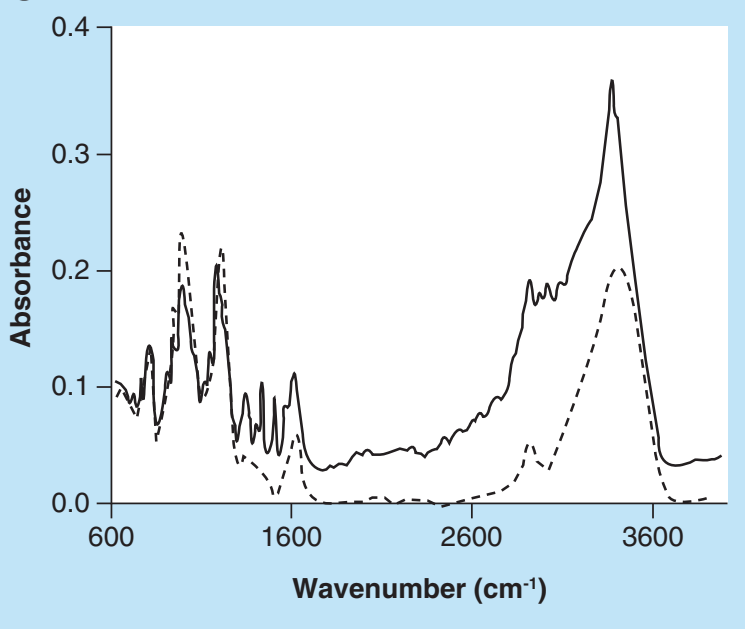

Figure 14. Fourier transform IR scans of the pigment made from (2) and fucoidan (solid line in both panels) and (2) (dashed line in panel A) or fucoidan (dashed line in panel B).

at a concentration of $10 \mathrm{mg} / \mathrm{ml}$ and a 10 - and 100 -fold dilution of both stock solutions were prepared for this experiment. The results show that, while CS A had a minimal effect on the IL-1 $\beta$ release from the immune cells, the pigment material induced the release of significant amounts of IL-1 $\beta$. In addition, both CS A and the pigment material did not affect the viability of the immune cells. In the case of IL-6 release, the effect of the pigment material appeared to deviate from the effect of CS A when the pigment was tested at a higher concentration.

\section{Discussion}

As for CAs, select PS promote the auto- and $\mathrm{Cu}^{2+}$-mediated oxidation of (1) and related compounds resulting in the formation of pigment materials. The transformation of CAs into MN-like pigments is described through the so-called Raper-Mason scheme as discussed elsewhere [22]. In this scheme, CAs undergo oxidation and cyclization into indole types of structures prior to the formation of the $\mathrm{MN}$ pigment. Unlike the reactions involving CAs, the reactions involving (1) or (2) appeared not to generate a chromophore with distinct features in its UV-Vis spectrum 


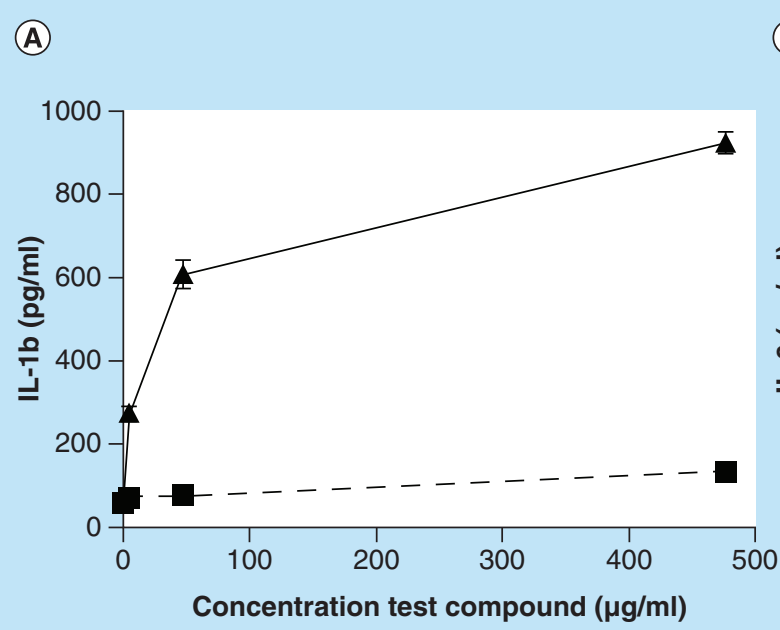

(B)

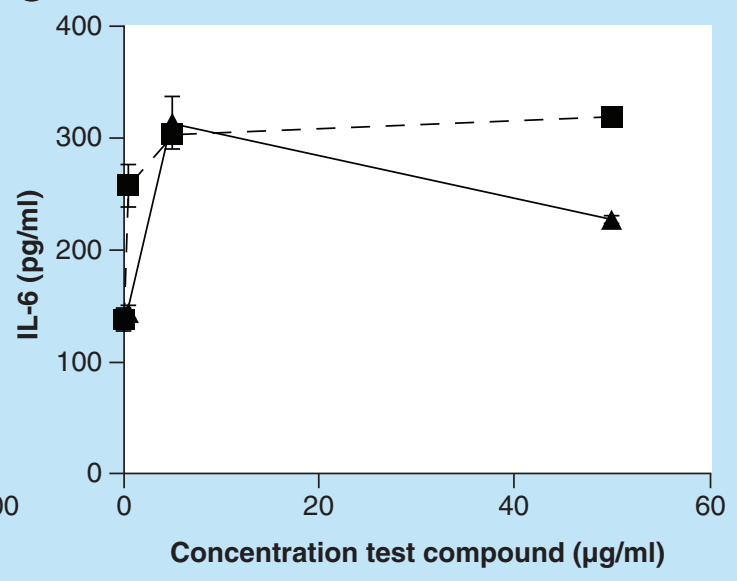

Figure 15. Interleukin release by serotonin-based melanin. IL-1 $\beta$ (panel A) or IL6 (panel B) release from immune cells in the presence of chondroitin sulfate type A (solid squares) and the pigment (solid triangles) made from (1) and chondroitin sulfate type $\mathrm{A}$ in the presence of $\mathrm{Cu}^{2+}$ as shown in Figure 8.

prior to the generation of the darkly colored pigment. Although, for both compounds, the oxidation reactions did lead to the formation of, as of yet unidentified, reaction products that could be resolved from (1) or (2) and other compounds through RP-HPLC or SEC analyses. The oxidation of (3) in the presence of select PS did lead to the formation of a chromophore with distinct features in its UV-Vis spectrum (see Figures 11 \& 12), but this chromophore appeared not to react further to a high molecular mass type of pigment as CAs and (1) or (2) do.

The same types of PS that are capable of promoting the transformation of CAs into MN-like pigments, appear to enhance the oxidation of (1) and (2) into pigmented substances that, in color and SEC profile, resemble the MN-like pigments generated from CAs. Although auto-oxidation of both compounds, particularly in the presence of CARRA or FUCO, can be achieved, the reactivity is greatly enhanced with increasing concentrations of $\mathrm{Cu}^{2+}$ (see Figures 3 \& 4).

SEC analysis of select pigmented materials generated from (1) in the presence of PS indicates that a fraction of the pigment is associated with the PS material and that another fraction of the pigment is associated with some material with much higher molecular mass than the original PS (see Figure 9). MNs formed from CAs have been observed to exist in nanoparticulate form [23,24]. Thus, it is not inconceivable that pigments generated from (1) in the presence of PS could exist as PS-stabilized nanoparticles.

The $\mathrm{Cu}^{2+}$-mediated oxidation of (1) in the presence of PS like CS A leads to the formation of an unidentified reaction product that can be resolved from (1) and PS materials through SEC analysis (see Figures $5 \& 9$ ). Jones et al. and Dai et al., in their studies of the Cu-induced oxidation of (1), identified a dimeric compound, 5,5'-dihydroxy-4,4'-bitryptamine and its isomers, as reaction products [20,25]. However, the unidentified reaction product generated in our experiments is not removed through dialysis using a membrane with molecular weight cut-off of $3.5 \mathrm{kDa}$ (see Figure 9), hinting that it represents a high molecular mass compound. This suggests that the unknown product generated in our experiments is unlikely to be 5,5'-dihydroxy-4,4'-bitryptamine.

The FT-IR spectra obtained of pigmented materials generated from (1) (see Figure 13) or from (2) (see Figure 14) in the presence of select PS, contain the presence of a distinct peak that is not present in the FT-IR spectra of the PS and that is present in the spectra of (1) or (2). Comparing the spectrum of CS A to the spectrum of the CS A/pigment material in Figure 13, panel B, the sharp peak at about $3390 \mathrm{~cm}^{-1}$ stands out. Such a sharp peak is also present in the spectrum of (1) as seen in Figure 13, panel A. Comparing the spectrum of FUCO to the spectrum of the FUCO/pigment material in Figure 14, panel B, a small, sharp peak at about $3393 \mathrm{~cm}^{-1}$ can be observed. Such a sharp peak at that wavenumber is present in the spectrum of (2) as shown in Figure 14, panel A. FT-IR spectra of indole types of compounds show sharp peaks around $3390 \mathrm{~cm}^{-1}$ and these have been attributed to an asymmetric NH stretching band [26,27]. Thus, FT-IR spectra of the pigments generated from (1) or (2) do contain 
chemical signatures different from those of the PS and these cannot be attributed to (1) or (2) as any unreacted starting material was removed through the dialysis process.

The FT-IR results indicate that the materials obtained are hybrids consisting of PS and pigment components; similar to what was observed for the experiments involving CAs [28]. Thus, any characterization of these materials faces the difficulty of trying to distinguish between PS starting material and pigment material. More recently, our research group has been using a different approach for generating MN-like pigments from a wide variety of precursors including (1) [29,30]. This approach does not require the presence of any PS or other biomolecule and may yield intermediates and/or final products that can be more readily characterized. At this stage it is unclear whether the presence of PS leads to MN-like pigments according to the classic Raper-Mason scheme. However, the fact remains that the presence of PS and redox-sensitive cations is sufficient to convert a multitude of catecholic or phenolic precursors into MN-like pigments. This current report and other results that we have reported upon do indicate that the study of the in vitro or in vivo formation of MN-like pigments may be complicated by the facts that nonenzymatic biomolecules (e.g., PS, proteins), a multitude of different precursors (dihydroxyphenylalanine [DOPA], catecholamines, serotonin, etc.) and/or different oxidizing conditions $\left(\mathrm{O}_{2}\right.$-mediated or $\mathrm{H}_{2} \mathrm{O}_{2}$-mediated oxidation) all could make a contribution to the final pigment product [28-33].

Apart from its importance in neurochemistry, the links between (1), its receptors and transporters and the immune system are the focus of intense research as reviewed elsewhere [34]. Peripheral sources release (1) into the bloodstream or lymphatic tissues for interaction with the various components of the innate or adaptive immune system [34]. The enterochromaffin cells of the GI tract are such an important peripheral source of (1) [35]. It is interesting to note that the presence of a greyish-brown pigment in the cytoplasm of such cells had been described more than 40 years ago [36]. Among the multiple effects of (1) on the components of the immune system, is its capacity to modulate the release or synthesis of proinflammatory cytokines like IL-1 $\beta$ [34]. In addition, (1) is capable of promoting the release of IL-6, for example, from rat adrenal zona glomerulosa cells [37]. Therefore, we briefly investigated whether pigments derived from (1) could affect the release of IL-1 $\beta$ or IL-6 from immune cells. As shown in Figure 15, panel A, pigment material generated from (1) in the presence of CS A significantly increased the amount of IL- $1 \beta$ from immune cells in a dose-dependent fashion. CS A had only a modest effect on the release of IL-1 $\beta$. In contrast, CS A promoted the release of IL- 6 in a dose-dependent fashion. The pigment material generated from (1) in the presence of CS A, tested at the lowest concentrations, appeared to have a similar effect on the IL- 6 release as CS A, while when tested at higher concentrations, the IL-6 release in the presence of the pigment material was reduced with about $30 \%$ compared with CS A. This may be an indication that the pigment/polysaccharide complex may induce a biomodal effect on the IL-6 release as is not uncommon for IL-6 [38]. It is worth noting that a study involving the effect of a pheomelanin-based pigment, conjugated to fibrillated $\beta$-lactoglobulin, induced the expression in microglia of multiple proinflammatory genes, for example, $i N O S, I L-1 \beta$ or $C O X-2$ [39].

\section{Conclusion}

We have demonstrated that MN-like pigments can be generated from serotonin and other 5-hydroxyindoles through a nonenzymatic mechanism involving PS and that such PS-pigment complexes can affect the interleukin release from immune cells.

\section{Future perspective}

Given the important functions of serotonin in the human physiology, including as a key neurotransmitter in the CNS, the authors would like to raise the hypothesis that serotonin, next to dopamine or norepinephrine, could make a contribution to the appearance of MN-like pigments in many brain areas. In addition, the authors would like to raise the hypothesis that PS, intra- or extracellular, could make an important contribution to the synthesis and storage of MN-like pigments.

\section{Author's contributions}

$K$ Vercruysse: conceived the scientific ideas behind the manuscript. Designed the experiments related to the synthesis and characterization of the pigments. Principal author of the manuscript. M Whalen: designed the experiments related to the interleukin release from immune cells. Principal co-author of the manuscript. A Clark and N Alatas: executed the experiments and processed the data related to the synthesis and characterization of the pigments. D Brooks and $\mathrm{N}$ Hamza: executed the experiments and processed the data related to the interleukin release from immune cells. 


\section{Summary points}

- Many polysaccharides, in the presence of $\mathrm{Cu}^{2+}$, promote the formation of melanin-like pigments from serotonin and other 5-hydroxy indole.

- Size-exclusion chromatography and Fourier transform IR analyses indicate the formation of high molecular mass polysaccharide/pigment complexes.

- Polysaccharide/pigment complexes may alter the level of interleukin release from immune cells.

Financial \& competing interests disclosure

The research and A Clark were in part supported by a grant from the US Department of Education [\#P031B090214]. Part of the research was supported by grants U54CA163066 and 2T34GM007663 from the National Institutes of Health. N Alatas was supported by the Saudi Arabian Cultural Mission to the USA. The authors have no other relevant affiliations or financial involvement with any organization or entity with a financial interest in or financial conflict with the subject matter or materials discussed in the manuscript apart from those disclosed.

No writing assistance was utilized in the production of this manuscript.

Ethical conduct of research

The authors state that they have obtained appropriate institutional review board approval or have followed the principles outlined in the Declaration of Helsinki for all human or animal experimental investigations. In addition, for investigations involving human subjects, informed consent has been obtained from the participants involved.

\section{Open access}

This work is licensed under the Creative Commons Attribution 4.0 License. To view a copy of this license, visit http://creativecomm ons.org/licenses/by/4.0/

\section{References}

Papers of special note have been highlighted as: $\bullet$ of interest; $\bullet \bullet$ of considerable interest

1 Vercruysse KP, Clark AM, Bello PaF, Alhumaidi M. Using size exclusion chromatography to monitor the synthesis of melanins from catecholamines. J. Chromatogr. B 1061-1062, 11-16 (2017).

2 Barnes NM. 5-HT: the promiscuous and happy hormone! Curr. Opin. Pharmacol. 11(1), 1-2 (2011).

3 D'ischia M, Wakamatsu K, Cicoira F et al. Melanins and melanogenesis: from pigment cells to human health and technological applications. Pigment Cell Melanoma Res. 28(5), 520-544 (2015).

- Recent reviews on the physico-chemical and biological properties of melanins, including neuromelanins.

4 Zucca FA, Segura-Aguilar J, Ferrari E et al. Interactions of iron, dopamine and neuromelanin pathways in brain aging and Parkinson's disease. Prog. Neurobiol. 155, 96-119 (2017).

- Recent reviews on the physico-chemical and biological properties of melanins, including neuromelanins.

5 Usunoff KG, Itzev DE, Ovtscharoff WA, Marani E. Neuromelanin in the human brain: a review and atlas of pigmented cells in the substantia nigra. Arch. Physiol. Biochem. 110(4), 257-369 (2002).

6 Zecca L, Bellei C, Costi $\mathrm{P}$ et al. New melanic pigments in the human brain that accumulate in aging and block environmental toxic metals. Proc. Natl Acad. Sci. USA 105(45), 17567-17572 (2008).

-. Offers recent insights on the characterization of neuromelanins found in the brain.

7 Biesemeier A, Eibl O, Eswara $\mathrm{S}$ et al. Elemental mapping of neuromelanin organelles of human substantia nigra: correlative ultrastructural and chemical analysis by analytical transmission electron microscopy and nano-secondary ion mass spectrometry. $J$. Neurochem. 138(2), 339-353 (2016).

-• Offers recent insights on the characterization of neuromelanins found in the brain.

8 Engelen M, Vanna R, Bellei C et al. Neuromelanins of human brain have soluble and insoluble components with dolichols attached to the melanic structure. PLoS ONE 7(11), e48490 (2012).

-. Offers recent insights on the characterization of neuromelanins found in the brain.

9 Fedorow H, Tribl F, Halliday G, Gerlach M, Riederer P, Double KL. Neuromelanin in human dopamine neurons: comparison with peripheral melanins and relevance to Parkinson's disease. Prog. Neurobiol. 75(2), 109-124 (2005).

10 Sulzer D, Bogulavsky J, Larsen KE et al. Neuromelanin biosynthesis is driven by excess cytosolic catecholamines not accumulated by synaptic vesicles. Proc. Natl Acad. Sci. USA 97(22), 11869-11874 (2000). 
11 Zecca L, Stroppolo A, Gatti A et al. The role of iron and copper molecules in the neuronal vulnerability of locus coeruleus and substantia nigra during aging. Proc. Natl Acad. Sci. USA 101(26), 9843-9848 (2004).

12 Zhang W, Phillips K, Wielgus A et al. Neuromelanin activates microglia and induces degeneration of dopaminergic neurons: implications for progression of Parkinson's disease. Neurotox. Res. 19(1), 63-72 (2011).

13 Kastner A, Hirsch EC, Lejeune O, Javoy-Agid F, Rascol O, Agid Y. Is the vulnerability of neurons in the substantia nigra of patients with Parkinson's disease related to their neuromelanin content? J. Neurochem. 59(3), 1080-1089 (1992).

14 Bertazzo A, Favretto D, Costa CV, Allegri G, Traldi P. Melanogenesis from 5-hydroxytryptamine, 5,6- and 5,7-dihydroxytryptamines. An in vitro study using MALDI-TOF. Adv. Exp. Med. Biol. 467, 779-787 (1999).

15 Roberts RD, Fibuch EE, Elisabeth Heal M, Seidler NW. Production of a novel neuromelanin at the sevoflurane-water interface. Biochem. Biophys. Res. Commun. 363(1), 77-81 (2007).

16 Smaniotto A, Comai S, Bertazzo A et al. A mass spectrometric investigation on the possible role of tryptophan and 7-hydroxytryptophan in melanogenesis. J. Mass Spectrom. 41(7), 921-930 (2006).

17 Miller ED, Fibuch EE, Seidler NW. Toxicity of a serotonin-derived neuromelanin. Biochem. Biophys. Res. Commun. 391(2), 1297-1300 (2010).

18 Eriksen N, Martin GM, Benditt EP. Oxidation of the indole nucleus of 5-hydroxytryptamine and the formation of pigments: isolation and partial characterization of a dimer of 5-hydroxytryptamine. J. Biol. Chem. 235, 1662-1667 (1960).

19 Martin GM, Benditt EP, Eriksen N. Enzymic oxidation of the indole nucleus of 5-hydroxytryptamine: properties of an enzyme in human serum and of the products of oxidation. Arch. Biochem. Biophys. 90, 208-217 (1960).

20 Jones CE, Underwood CK, Coulson EJ, Taylor PJ. Copper induced oxidation of serotonin: analysis of products and toxicity. J. Neurochem. 102(4), 1035-1043 (2007).

21 Meyer TPH, Zehnter I, Hofmann B et al. Filter buffy coats (FBC): a source of peripheral blood leukocytes recovered from leukocyte depletion filters. J. Immunol. Methods 307(1-2), 150-166 (2005).

22 Simon JD, Peles DN. The red and the black. Acc. Chem. Res. 43(11), 1452-1460 (2010).

23 Xiao M, Li Y, Allen MC et al. Bio-inspired structural colors produced via self-assembly of synthetic melanin nanoparticles. ACS Nano 9(5), 5454-5460 (2015).

24 Wolbarsht ML, Walsh AW, George G. Melanin, a unique biological absorber. Appl. Opt. 20(13), 2184-2186 (1981).

25 Dai Z, Chauhan S, Green TK. Synthesis and enantioseparation of atropisomers of serotonin dimer. Tetrahedron Lett. 56(26), 4022-4024 (2015).

26 Bayarı S, Saglam S, Ustundag HF. Experimental and theoretical studies of the vibrational spectrum of 5-hydroxytryptamine. J. Mol. Struct. 726(1-3), 225-232 (2005).

27 Suwaiyan A, Morsy MA. Ab initio calculations and vibrational spectra of 5-methoxy indole. Spectrochim. Acta A Mol. Biomol. Spectrosc. 53(4), 575-588 (1997).

28 Vercruysse KP, Clark AM, Bello PaF, Alhumaidi M. Using size exclusion chromatography to monitor the synthesis of melanins from catecholamines. J. Chromatogr. B Analyt. Technol. Biomed. Life Sci. 1061-1062, 11-16 (2017).

29 Vercruysse K, Russell S, Knight J, Stewart N, Wilson N, Richardson N. Dark- or light-colored melanins: generating pigments using Fe ${ }^{2+}$ and $\mathrm{H}_{2} \mathrm{O}_{2}$. Chemrxiv doi:10.26434/chemrxiv.5645674.v1 (2017) (Epub ahead of print).

30 Vercruysse K, Taylor A, Knight J. $\mathrm{Fe}^{2+} / \mathrm{H}_{2} \mathrm{O}_{2}$-mediated oxidation of homogentisic acid indicates the production of ochronotic and non-ochronotic pigments. Implications in alkaptonuria and beyond. bioRxiv doi:10.1101/223099 (2017) (Epub ahead of print).

31 Vercruysse K, Clark A, Alatas N, Brooks D, Hamza N, Whalen M. Polysaccharide-mediated synthesis of melanins from serotonin and other 5-hydroxy indoles. bioRxiv doi:10.1101/184002 (2017) (Epub ahead of print).

32 Vercruysse K, Tyler L, Readus J. Gum Arabic promotes oxidation and ester hydrolysis. bioRxiv doi:10.1101/199711 (2017) (Epub ahead of print).

33 Vercruysse KP, Farris TS, Whalen MM. Interleukin-1 $\beta$ and -6 release from immune cells by DOPA-based melanin as free pigment or complexed to carboxymethylcellulose. bioRxiv doi:10.1101/185140 (2017) (Epub ahead of print).

34 Baganz NL, Blakely RD. A dialogue between the immune system and brain, spoken in the language of serotonin. ACS Chem. Neurosci. 4(1), 48-63 (2013).

35 Gershon MD, Drakontides AB, Ross LL. Serotonin: synthesis and release from the myenteric plexus of the mouse intestine. Science 149(3680), 197-199 (1965).

36 Derizhanova IS. [Melanosis of the large intestine]. Arkh. Patol. 37(11), 54-59 (1975).

37 Ritchie PK, Knight HH, Ashby M, Judd AM. Serotonin increases interleukin-6 release and decreases tumor necrosis factor release from rat adrenal zona glomerulosa cells in vitro. Endocrine 5(3), 291-297 (1996).

38 Van Kralingen C, Kho DT, Costa J, Angel CE, Graham ES. Exposure to inflammatory cytokines IL-1 $\beta$ and TNF $\alpha$ induces compromise and death of astrocytes; implications for chronic neuroinflammation. PLoS ONE 8(12), e84269 (2013). 
39 Ferrari E, Capucciati A, Prada I et al. Synthesis, structure characterization, and evaluation in microglia cultures of neuromelanin analogues suitable for modeling Parkinson's disease. ACS Chem. Neurosci. 8(3), 501-512 (2017). 